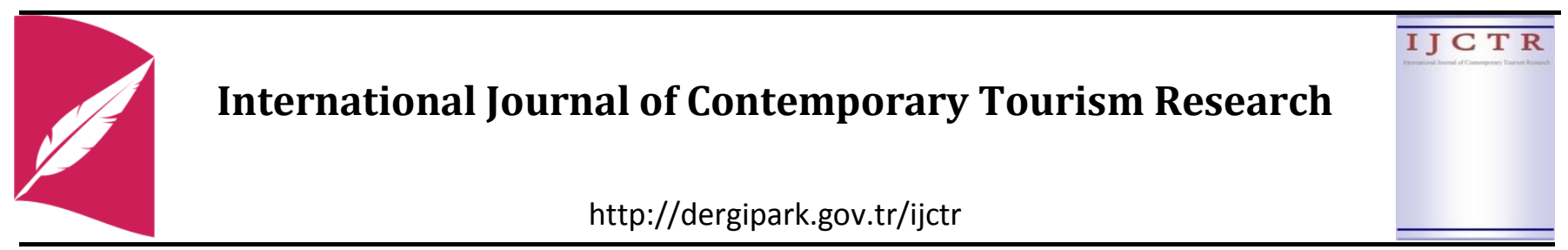

\title{
AUGMENTED REALITY APPLICATIONS IN TOURISM
}

\section{Research Article}

\author{
Emrah ÖZKUL ${ }^{1}$, Sarp Tahsin KUMLU ${ }^{2}$
}

\begin{abstract}
This study aims to examine the use of the application in tourism field on the question of what augmented reality applications mean, which is one of the endpoints of technology for tourism. With the study of in-depth literature, firstly augmented reality has been determined, and the changes and developments it has undergone throughout the history have been examined. Then, its areas of use and the types have been examined.

Today, it is thought that the augmented reality, being the newest dimension of technology and seems it is almost impossible not to use in the area of tourism will provide a huge amount of marketing convenience and competitive advantages. In this article, twelve case studies on the application used in many fields of tourism such as transportation, accommodation, food \& beverage and museums, have been analyzed. As a result of these analyses, it is seen that augmented reality applications, which are used in this field increasingly, provide a great marketing convenience to businesses and destinations. Augmented reality applications, playing a major role in the travels of tourists, make consumers feel safer while making the travels easier. It is thought that all businesses that want to capture market progress in the coming years and aim to provide competitive advantage by making a difference in influencing tourists will intensively use augmented reality applications.
\end{abstract}

Keywords: Augmented Reality, Tourism, Augmented Reality Benefit, Augmented Reality Challenge

Jel Classification Codes: L83, N7, M31

\footnotetext{
1 Assoc. Prof. Dr., Kocaeli University, Tourism Faculty, Department of Tourism Management, emrahozkul@hotmail.com, orcid.org/0000-0002-7938-6916

2 M.Sc. Candidate, Kocaeli University, Graduate School of Social Sciences, Department of Tourism Management, sarptahsinkumlu@ hotmail.com, orcid.org/0000-0002-8350-3329

“Özkul E., Kumlu S. T. (2019). Augmented Reality Applications in Tourism, International Journal of Contemporary Tourism Research, Vol 3: No: 2, p.107-122, doi: 10.30625/ijctr.625192"

Received Date: 26.09.2019 Accepted Date: 05.12.2019
} 


\section{INTRODUCTION}

The tourism industry has developed throughout the history, mostly in parallel with technology, and has built its activities on attracting the tourists' attention, raising curiosity and meeting the expectations. The use of technology in tourism industry has an essential role in attracting the turists and creating competition among destinations and businesses. The developments in information technologies enable destinations and all businesses in the tourism chain to offer new opportunities in management, marketing and advertising activities and provide advantage in competition (Krevelen \& Poelman, 2010). On the other hand, with the increase of the internet usage, the profiles of tourists can be said to have changed due to the social media effect on people and there have been differences in the expectations and behaviors of tourists. One of the technological developments of today is the "augmented reality" with a constantly expanding application field. Augmented reality is defined as a new technology that involves implementing computer graphics into the real world (Silva et al., 2003). In the system, which benefits from the software and hardware relationship, there are many features for the benefit of business/user which are complexity, user content, ethical issues, and cost and privacy policies. It is observed that applications are used in many sectors such as education, medicine, military, games and movies (Alkhamisi \& Monowar, 2013).

Augmented reality applications are not extensively used in tourism today. While users experience a destination with augmented reality applications, they also have the opportunity to explore many features with their imagination. In addition, tourists are provided with more detailed information about their activities in the destinations they visit, and tourists who visit any destination with mobile technology infrastructure benefit from various services through mobile travel guides and location detection. Nowadays, augmented reality applications are used in the field of exhibiting and digitally re-creating the first works of historical artifacts found in museums. It is foreseen that this practice will intensify in the accommodation enterprises within the next few years (Jung \& Han, 2014).
It is aimed to be used in areas such as directing the guests to the room and sudden changes in the room designs according to the wishes of the guests. When it comes to food and beverage services, restaurants, which are aware of their customers' meal preferences with smart table applications, will gain quality and competitive advantage with augmented reality applications to provide fast and high-quality service. It is anticipated that many enterprises operating in tourism sector will benefit from the applications in order to provide tourist satisfaction and create a competitive advantage comparing to the other enterprises in the future.

In this study, augmented reality applications, which are one of the latest applications of technology, are defined. Besides, its history, usage in tourism and the points to which it may reach in the following years are emphasized. Then, the current applications usage in tourism field has been evaluated and the benefits and harms that it has brought about to the areas that has been used are discussed.

\section{AUGMENTED REALITY CONCEPT}

The concept of augmented reality emerged as a new field of virtual reality and computer technology towards the end of the 90 s and has spread to a wider area (Pagani et al., 2016).

Augmented reality technologies are defined in different ways by many scientists. Azuma (1997) defined it as a variant of virtual environments or virtual reality technologies that attract users to a synthetic environment. Edwards - Stewart, Hoyt and Reger (2016) have argued that they can be evaluated differently and classified separately. Approving the previous statement, Sirakaya \& Seferoğlu (2016) define it as "While the real situation in the virtual reality environment is carried to the virtual world, the augmented reality environment is enriched with the data in the digital environment transmitted to the real world". Augmented reality is a form of technology produced and developed by superimposing images on objects through computers (Jacob et al., 2012). Carmigniani et al., (2011) defined it as creating a direct or indirect image of the real-world environment as by adding information on the world created virtually via computers. Siltanen (2012) suggests that these are applications that provide interaction between objects that use graphics to combine digital data with the real 
world. Tülü \& Y1lmaz (2013) define it as the technology designed by the developer, appearing on the determined image of the three-dimensional object that genuinely creates an effect on the image while looking at the predetermined target images with the mobile device cameras. Direct or indirect perspectives in the physical and real world, where computer-generated elements are enhanced by sensory input, are referred as augmented reality (Edwards-Stewart et al., 2016). Reitmayr and Schmalstieg (2003) defined it as an interface technology that strengthens the user's environment with data created by computer technology.

When all the definitions given above are evaluated, augmented reality applications are considered as an advanced technology that provides an indirect point of view to consumers as a result of implementing visuals obtained with highresolution cameras into the virtual environment through advanced computers. As a very new and attractive experience for people, the application offers users great experiences with special corded clothing sets, goggles, helmets, gloves and special shoes. In addition, augmented reality applications, which are increasingly used nowadays, provide user convenience in interaction with mobile devices and tablets they have.

\section{The History of Augmented Reality}

Although AR has a history dating back to the end of the first half of the 19th century, until the late 1990 s, it was used only by scientists because of the high prices, complicated hardware and software. It took almost half a century for the application to meet the regular consumer. The ARToolKit resource presented by Kato has played a major role in the development of AR applications. With this resource, the introduction of software kits and developers to experiment on the application is called the beginning of a revolution (Cranmer, 2017). Arth et al., (2015) associates the first example of the application with the experiential development of wearable AR on the move. With the implementation of the wearable technology on the mobile device display, a new concept, the mobile device AR, has emerged. The increase in the use of the application has progressed in a sustainable form. Nowadays, the use of augmented reality applications, which are spread over a wide area, is increasing day by day as individual and institutional.

\section{Future Usage of Augmented Reality}

Krevelen (2007) emphasizes that in the coming years, humanity will experience some changes in the way of perception of reality owing to virtual empowerment and in this context, augmented reality applications will emerge as advanced technologies that will be beneficial for the users in many areas of sight, hearing and feeling. The augmented reality applications, defined as the latest technology in which many industries are highly sensitive to provide a competitive advantage, are now started to be used in mobile devices, sports fields and education fields. However, it is thought that the application developed by researches in high institutes will have a great place in thehuman activity field in the following years (Alkhamisi et al., 2013). Mekni and Lemieux (2014) suggest that in future studies, the HMD's and wearable equipment created by the application should be improved to be lighter and smaller.

Figure 1: Evolution of User Experience from Virtual Reality to Augmented Reality
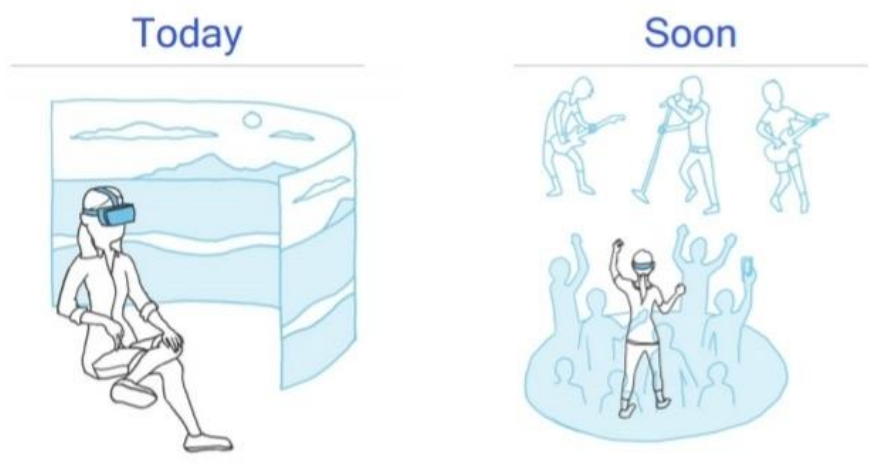

The future

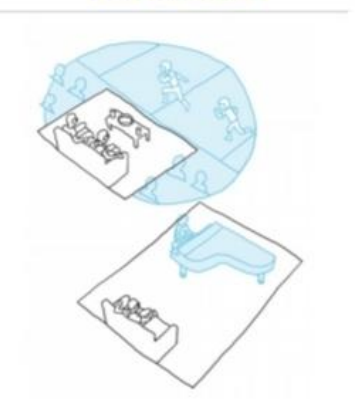

Source: Qualcomm Technologies, 2018 
Figure 1 shows that the world of AR that we interact with in a digital environment through a pair of glasses today, in addition to having a bigger part in our social life, it might also take over the center of our lives in the coming years.

\section{Augmented Reality Applications in Tourism}

Ramos et al., (2018) argue that augmented reality practice is a blooming industry that plays a mandatory role in defining traditional tourism and that the data on the tourists' mobile screen becomes more exciting with the overlay method. The application aims to increase the tourism experience and maximize the level of entertainment, as well as assisting tourists to access their information and to improve their knowledge of destination attraction (Kounavis et al., 2012). AR applications offer unknown regions as tourism activities in a fun and interactive way and with the increase in usage, it provides the opportunity to develop the visitor experience to destinations and tourism organizations (Dieck \& Jung, 2015). Emphasizing the necessity of using modern technology, Han et al., (2014) recommends that many destinations should be tailor-made in order to remain competitive and attractive for tourists, and recommends the use of the new type (AR), usage of which is gradually increasing. However he also addresses that it has not yet reached the desired potential and population, but it will become a major technology in the future and the tourism industry should use this position well. Buhalis et al., (2012) argue that paradigms arising from AR synergy have the potential to enhance the tourist experience and make them high-level, adding that elaborate and applicable technologies which provide information to tourists at all times and conditions are no longer a future dream. However, it has been suggested that it is still in the beginning stage. Many applications can be mentioned in many areas of tourism. One of these applications, Tuscany AR, works as a tourism guide developed by Tuscany, especially for Tosda region. Wikipedia cooperates with many portals and guides tourists about accommodation, food \& beverage, nightlife and nature trips with the information taken from sources. Layar is a project that has been created for the city of Basel. It provides the tourist with all information about restaurants and bars, museums, shopping centers, events and excursions, guided tours and leisure places in and around Basel. All operating systems work in a competence with one another. Urban Sleuth has been developed by Urban interactive as an adventure city where users participate in solving mysteries and performing missions while visiting the city. This application plays a major role in the integration of the real world and the virtual world. The design of the application can be done to allow tourists to find monuments, museums and cultural heritage areas. Finally, the street museum app, which allows tourists to visualize the special and historical sites of London, has been designed specifically for London museum. People can get information by touching of a button after directing the cameras of the mobile devices to any point they wonder. The application also allows tourists to discover important points before starting the tour (Kesimati et al., 2012).

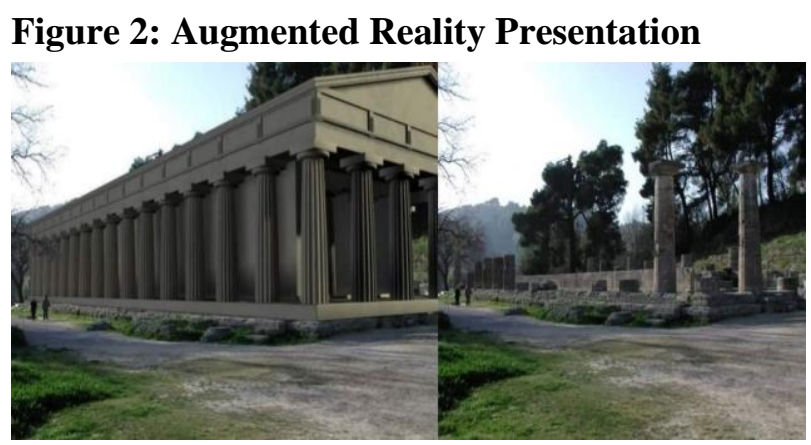

Source: Vlakhis et al. (2001)

Figure 2 shows that the cultural heritage remains are presented to the tourists by restoring them through AR without touching the structure at all. It is possible to say that the popularity of augmented reality applications in the field of tourism is increasing day by day in fields like museums, accommodation establishments, food and beverage establishments and transportation.

Vlahakis et al., (2001) discuss the project ARCHEOGUIDE (Augmented Reality-based Cultural Heritage On-site GUIDE) used in the field of cultural heritage by adapting it to tourism. The project provides a personal electronic guide and tour assistant for cultural site visitors in Europe. The application, which provides visitors with cultural data, restoration information, virtual tours, provides a lot of information about archaeological research and cultural tourism to tourists wishing to get information both for entertainment and professional purposes with its multi-mode user interface. 


\section{METHODOLOGY}

In this study, AR applications in the tourism sector and the benefits of these applications in terms of tourism, tourist and business will be examined through examples. The selection of the samples to be examined is based on sub-branches of the tourism sector such as; museums, accommodation companies, food and beverage industry, tourism destinations and transportation companies. Various examples have been studied for each tourism subsector. These selected examples have been chosen not to generalize the tourism applications but to examine different application examples. Analyzing the applications in accordance with AR is suitable for inductive reasoning in the field of tourism. However; it is not one of the main objectives of this study. After examining the selected samples, the properties will be summarized and interpreted in a table.

\section{Museums}

\section{ArtLens 2.0, Cleveland Museum of Art}

ArtLens 2.0, one of the most important applications designed and developed by museums, is used in the Cleveland art museum. The application was launched as a result of a 6-month trialin 2016. The purpose of the application is to present visitors' preferences and interests in $2 \mathrm{D}$, using image recognition software. In addition, the application which records and models the conversations among visitors creates a vibe. The application also provides great convenience to the visitors by means of the ability to discover new roads with the map feature, reach the desired place faster. Besides it can also warn them when they approach to the special works. The application that displays all artworks in real time uses Bluetooth technology for the Collection Wall, a 40-meter interactive, multi-touch, MicroTile wall. The ArtLens 2.0, which includes all these features, can be downloaded and used in approximately one minute on Google Play and App Store. Jane Alexander, chief information officer of the Cleveland Museum of Art, claims that this application is different from other applications because it has a dynamic structure that updates the name, date, tombstone information, didactics, videos and gallery location in real time (Ding, 2017).
- Target Group: Groups who visit the museum.

- Augmented Realty Type: Image-Based, Projection-Based

- Benefit for Tourist: Firstly, it increases the interaction with the work by presenting the works to the visitors in two dimensions. In addition, it enables the tourist to have fun with the sound recording and a lively environment. Thanks to its easy download and usage features, it provides visitors with interactive and different experiences within the museum without any difficulty.

- Benefit for Operating: Visitors not only examine the artifacts in the museum but also get many different experiences. This maintains the sustainability of the business for a visitor by increasing their desire to visit again.

- Benefit to Tourism Marketing: The application increases the likelihood of a tourist coming back to the museum, since it provides an interactive experience by including the tourist into the museum experience. The tourist who has fun with the gameplay feature of the AR application can increase the demand for the museum by giving feedback to his surroundings and sharing it on social media. All these benefits are important and necessary for tourism marketing.

\section{Layar the Blanton Museum}

From December 2015 to April 2016, the Blanton Art Museum at the University of Texas at Austin used Layar AR to provide visitors with interpretative information for the exhibition "The Crusader Bible: A Gothic Masterpiece". A number of tests were conducted 2 hours before using the application available in both iOS and Android. The management of the museum has emphasized that the artifacts should be explained spectacularly and in an informative way. The management, who thought it would be difficult to present it because the works exhibited in the performances contain languages such as Persian and Latin, achieved very good results by using the Layar AR application compatible with mobile devices and iPads for free. During the exhibition, it was determined that an average of 2000 of the 9800 visitors used the Layar application. "The app definitely added an additional layer of interpretation that would have been almost impossible to deliver via traditional 
labels. Given the subject matter of the exhibition, visitors were more eager than usual to engage with the narrative of the works themselves, and the app enabled them to do that" (Ding, 2017).

- Target Group: All tourists who visit the region.

- Augmented Reality Type: Identification-Based

- Benefit for Tourist: First of all, the tourists visiting the museum had the opportunity to listen to all the details they had been curious about in their own language. In addition, the tour became interesting and entertaining and mediocrity disappeared by means of the application.

- Benefit for Operating: First of all, the museum creates a competitive difference with a guide organization that will not have any problems in language and expression. In addition, an interesting and entertaining presentation will promote the desire of tourists to come back or suggest.

- Benefit to Tourism Marketing: The tourists who are satisfied and want to come again will create a great advantage for the sustainable marketing of the area and their word of mouth marketing will provide the region with a competitive advantage. In this respect, it is thought that if the region that satisfies the tourists presents the current data correctly in the marketing efforts to attract new tourists, it will make a great difference.

\section{Story of Forrest the National Museum of Singapore}

The Singapore National Museum is currently using an installation called "Forest Story". In the exhibition, 69 images from the William Farquhar Natural History Illustrations Collection have been transformed into three-dimensional animations that visitors can interact with. Visitors can use this application on their mobile devices or tablets. The application, known to be family-friendly, provides a learning experience. With the application very similar to Pokemon Go, visitors can search and capture items. They can then add the captured items to their virtual collections. After the items are collected, the applications flow information to the visitors about them. Users can learn facts such as habitat, diet and how rare the species are. The William Farquhar Natural History Drawings Collection is one of the most important collections of the museum. This AR project, created by the Japanese digital art collective team, Lab, makes the drawings as real as possible. Visitors can interact and explore images with excitement (Coates, 2019).

- Target Group: Tourists who visit Singapore.

- Augmented Realty Type: Image-Based, Projection-Based, Recognition-Based

- Benefit for Tourist: Tourists will not have a moment to get bored, as they will learn the information by playing a game at the museum. In addition, tourists travelling for leisure or recreational purposes, as well as cultural tourists will participate in different tours and have new experiences. The application, which provides a tour in which families with children can also participate, will increase the level of satisfaction by offering different activities to different types of tourists.

- Benefit for Operating: Thanks to the learning by playing system offered by the app, the museum which has a wide target audience has the chance to host many tourists. The fact that tourists get information by playing games enables them to move without any problems.

- Benefit to Tourism Marketing: It is considered that the application will be a great tool for the tourists to choose their destinations. Even tourists who think they are not suitable for cultural tours will want to experience this tour by playing the game. This shows how the application can play a major role in marketing of the region and attracting the target audience.

\section{Accommodation Businesses}

\section{Portal to Paradise, Marriott Hotels}

Marriott Caribbean \& Latin America Resorts has launched a new iOS app that uses augmented reality enabling consumers to explore its features to provide a striking insight into many dynamic destinations in the region. The application allows consumers to discover places they have never thought about before or places they have always wanted to see. It is designed to offer consumers a "walk" on every property and a 360-degree sea view so that they can experience the true taste of what they expect on vacation. Alex Fiz, vice president of the region, suggests that stepping into a holiday resort creates colorful and immersive 
experiences at each destination thereby it increases holiday planning or at least imagining the experiences the destination can offer. Salesand Marketing - Caribbean \& Latin America, Marriott International has made an explanation about this, "Having this vision will also enable travelers and travel planners to break the prejudices against destinations and see the truth.At this point, of course, the goal is that customers are inspired to book a trip to take over the Caribbean and Mexico firsthand"

App users are provided with a list of the available resorts to choose from, which they can change at any time. Each resort offers six different scenes to explore, including the pools, restaurants, beaches, rooms and spas. According to the Taylor (2018) "The AR views of physical, real-world environments create an incredibly life like experience that allows users to easily imagine actually being there." "Going beyond the typical image gallery on a resort's website, this app places consumers directly on property in such a realistic way that they can almost feel the ocean breezes and hear the waves outside hotel windows."

- Target Group: Consumers with accommodation potential at Marriott Caribbean \& Latin America Resorts.

- Augmented Realty Type: Location-Based, Image-Based

- Benefit for Tourist: People are excited to have different experiences especially when planning their holidays. They travel with high expectations. The application used in these institutions offers tourists an experience apart from the standard hotel activities. Tourists who experience this will feel very happy and pleased with their holidays.

- Benefit for Operating: In the service sector in which it is very difficult to meet the high expectations of the tourists, the institutions that have provided the highest level of expectations with the AR service offered besides the known services are able to be among the most recommended with the difference in word of mouth marketing as well as being the first that comes to mind in the next holiday plans.

- The Benefit to Tourism Marketing: Marketing tourism is quite difficult and risky. It is a necessity to follow the globalizing world due to the fact that it is individual oriented. This application can be defined as an opportunity that both institutions and destinations can exhibit their differencefor tourists. It should be emphasized that the destination is very important in terms of providing a competitive advantage in tourism marketing.

\section{Holiday Inn}

In 2012, Holiday Inn launched the first AR application for the Olympic and Paralympic Games held in London. The hotel enabled its guests the opportunity to see Olympic and Paralympic players through AR, in rooms, lobby and at reception. The application included BMX, windsurfing, table tennis and long jump athletes from the Olympics and Paralympics. Experiences were created by combining image recognition technology and chroma video. The app recognizes various hotel sites and combines the real environment with these virtual elements by scanning athletes' overlay video footage. BMX World Champion Shanaze Reade performed tricks on her bike in the lobby, while British windsurfer Nick Dempsey could be found in one of the guest rooms, windsurfing with a bed sheet. Guest could even engage in a game of table tennis with Paralympic world number 1 Will Bayley over the reception desk all through their own mobile devices. The Holiday Inn duffel bag is a good example of how hotels can use AR to create new experiences for their guests around key events happening at their destination. This attempt helped the hotel to promote themselves and strengthen its position as an official London 2012 Olympic and Paralympic Games hotel. In addition to creating value and new experiences for its guests, incorporating $\mathrm{AR}$ experiences throughout the hotel's application can be a great way to ensure and enhance the use of the application. AR plays a major role to stay before, during and after the system for hotel establishments (Martins, 2017).

- Target Group: Tourists traveling London and living in London.

- Augmented Realty Type: Projection-Based, Image-Based

- Benefit for Tourist: There are many hotels for tourists that they can stay during their London trip. However, especially the tourists who follow the Olympics or the athletes, are facing the possibility of encountering a surprise at any moment and any place where they point their 
cameras in the hotel. This makes the tourist excited to go to the hotel for new experiences besides relaxing and going to the hotel after the current tour.

- Benefit for Operating: The application firstlyattracts the famous athletes' attention to share and it enables the business to create new target groups. It also makes the business prior for tourists who will choose a hotel during their trip in London. In addition, it increases the desire ofrevisiting the hotel and makes tourists curious about the new events presented in the application.

- Benefit to Tourism Marketing: It is thought that it can be used by other businesses in the region since the application that offers a different experience to the tourists, brings the business to the forefront. This shows that AR will be used as a new marketing tool in the region. The application that gives tourists the experience of interacting with celebrities will increase the satisfaction of the tourists. It is foreseen that tourists who spend their holiday with high satisfaction will play a role in the marketing of destinations and will create a new audience as loyal guests.

\section{Best Western Hotels \& Resorts BWVRE}

Fast Company today announced its annual ranking of the world's Most Innovative Companies (MIC), honoring Best Western Hotels \& amp; Resorts with a spot in the Top 10 Most Innovative Companies in AR/VR category. The brand was recognized for its two-prong approach to VR/AR including the Best Western Virtual Reality Experience (BWVRE), which uses virtual reality to reinvent the way guests view and shop for hotels; and its I Care Every Guest Every Time employee training, which leverages virtual reality to transform communications between front desk staff and guests. These initiatives positioned Best Western as the first company of its size and scale to utilize this cutting-edge technology in these ways. The Best Western brand is determined to follow the latest technology to meet the needs of tourists. The management is pleased to see that the AR and VR technology has brought a new standard in the sector, and aims to maintain leadership in innovation and pioneering hospitality. BWVRE offers tourists the opportunity to test the hotel's public areas before booking or accommodation.
The application creates interactive tour opportunities for users in the hotels' pool, lobby, fitness center and room types with threedimensional 360-degree videos, exclusive narration and music. Customers can explore everything from interior design to product quality as they walk through the places. Travelers can now tour 2,200+ properties of Best Western in North America on all platforms supported by HTML5, including Google Maps, Google Search, YouTube and Facebook (BestWestern Hotels \& Resorts, 2018).

- Target Group: All potential tourists for Best Western hotels.

- Augmented Realty Type: Outline-based, Image-Based

- Benefit for Tourist: It is seen that trust, which is one of the most important conditions in the tourism industry for tourists, has been carried to high levels thanks to this application. The fact that all areas of the hotel can be used before booking and even the materials can be inspected, shows the transparency of the business. Thus, tourists can find out if this hotel is suitable for them during booking and they can develop solutions to the problems that may occur during the activity.

- Benefit for Operating: It is thought that the operation will not have any difficulty in expressing itself to the customers by means of the application that gives tourists the opportunity to evaluate the hotels almost completely before they visit. It will be much easier to avoid any complaints or meet any demands that may come from tourists thanks to the information has already been given within the application. In addition, tourists with questions in their minds before going on vacationwill be able to find answers through the application.

- Benefit to Tourism Marketing: The fact that tourists can observe the activities that they will experience before visiting the destination will increase the sense of trust between the enterprise and them. Trust, which is one of the most important points in tourism, can be the best marketing strategy that a region can use. In addition, the use of the application by the other businesses in the region will play a major 
role in creating loyal customers and ensuring sustainability.

\section{Food and Beverage Businesses}

\section{Smacar, Foodpath}

FoodPath is a multi-cuisine restaurant located in Mumbai, on the Agra National Highway. It offers purely vegetarian delights at affordable prices across Thane and other areas nearby. Smacar solutions created a design that reflects the colors of the client's logo and accommodates the beautiful and attractive photos of the food, enticing enough for the potential customers to visit the restaurant. By creating a custom product catalogue, the client could add images of the food, their prices and description on the website which allows the visitors to easily view all the menu items. To encourage people to come back time and again, smacar solutions integrated an augmented reality game which the customers can play by scanning the client's logo on printed materials such as flyers, menu card as well as the logo on their website. The game is based on a spin wheel concept which allows the players to win discount offers by spinning a virtual wheel. The Result: Smacar solutions created a brand new website that was easy to navigate for the visitors. The website was designed in a way to help the client to easily maintain and update the website regularly without any assistance from a technical team. The augmented reality-based spin wheel game helped to generate curiosity among the customers by providing them with interactive experiences in addition to winning discount offers. The game provided an opportunity for the client to get more out of the promotional materials such as flyers and entice their customers to visit their restaurant again (smacar.com/augmented-reality-case-studyrestaurants-case-study-restaurants/).

- Target Group: All potential tourists for the restaurant.

- Augmented Realty Type: Image-Based, Projection-Based, Recognition-Based

- Benefit for Tourist: Consumers whose expectations are a delicious meal and a good presentation, meet with many different experiences thanks to the application. It also provides the opportunity to have fun by playing games while eating their meal.

- Benefit for Operating: The company, strengthening the ordinary expectations shaped by ordinary services with different presentations, follows a positive way of creating a loyal audience by offering a new reason for customers to come again.

- Benefit to Tourism Marketing: This fun service presented in addition to eating and drinking will play a major role in prompting people to eat out. As eating out affects the flow of money in the market, the tourists who are curious and coming from outside will benefit the region's economy. The application, which is considered as a great tool in the marketing of tourism, will be a tool for some tourists yet it will be the target for the rest.

\section{Inamo Restaurant}

Inamo, which is described as the extraordinary restaurant known for its experience of Far East service in Western conditions, is located in London. The hospitable virtual environment such as e-table, chef camera, local area and taxi booking, is developing all over the world. Inamo restaurant also enables customers to order food and beverage with AR interactive menus placed on the tables. The tables operate with four electronic display cards as electronic sales point. There are waterproof touch panels which function with Bluetooth, high-quality projectors and interactive AR-guided computers on the tables. The mainserver includes a variety of tools that define the operational aspects of the restaurant, besides, the main server printers run in the bar and the kitchen. Inamo restaurant management aims to get the opinions of its guests through a semi-structured interview to better understand AR's perspective in the accomodation industry. As a result of the interview, it is concluded that the use of technology is appropriate in London and the guests have fun while eating (Shabani et al., 2018).

- Target Group: All consumers travelling to London and who live there and have the potential to go to the restaurant.

- Augmented Realty Type: Projection-Based, Image-Based, Location-Based

- Benefit for Tourist: With features like taxi booking, the app provides great convenience to customers. In addition, with its smart table feature, it offers both different experiences and the opportunity to have fun while eating.

- Benefit for Operating: The application increasing the level of customer satisfaction 
thanks to the convenience and fun processes that it provides, plays a big and positive role for the desires of the customers to come back and to leave withpleasure.

- Benefit to Tourism Marketing: With the application, customers will want to experience $\mathrm{AR}$ as a means, even if it is not the objective. For this reason, they will act with a desire to have an enjoyable meal outside. In addition, the application that offers a competitive advantage against other regions can be used as a promotion in the marketing of tourism.

\section{Bare Burger}

Burger chain Bare Burger has been one of the first to adopt this new AR technology, partnering with AR food menu app Kabaq to make their new meatless Impossible Burgers virtually appear on guests' plates through the Snapchat app. Bareburger customers can now view their shockingly realistic lunch before they even step up to the counter. In the study conducted by Kabaq, desserts have been first presented to the guests with tablets. Firstly, there has been a $25 \%$ increase in the tables which provides eating virtually. At the same time, AR Snapchat has developed an interactive marketing system by means of the programmable scanning (Kavanaugh, 2018).

- Target Group: Consumers who want to experience different restaurants in America.

- Augmented Realty Type: Projection-Based

- Benefit for Tourist: Tourists will be able to order their meal after viewing the way it is made and the final version of the meal. In this way, they can make more informed and free decisions about the dishes they really want to order instead of simply choosing from the menu.

- Benefit for Operating: Firstly, tourists who have reached a certain level of consciousness by viewing the cooking process and the final form of their meals will significantly ease the workload of the service staff. And the satisfaction level of the consumer who can see what he wants from the preparation to the end will rise and he will want to visit the restaurant again. This will make a major contribution to the sustainability of the company by serving the products the same as in the application.

- Benefit to Tourism Marketing: Tourists who are satisfied with their experience at the restaurant will want to repeat this and recommend the restaurant to their friends. This will enable the region to provide a competitive advantage with word of mouth marketing as well as its own marketing strategies.

\section{Transportation Businesses}

\section{Transportation Departures Switzerland}

Departures Switzerland shows all public transport options around users by means of augmented reality scanner. For users looking for the closest public transport option, the application allows the user to hold the phone towards the desired station or direction and the corresponding destination board is superimposed on the real-world view. Currently, the application is used on iPhone. Within the app there is a small arrow pointing to all public transport stops, trains, trams, buses, ships, ropeways and other types of transport, departure times, real-time information (delays and platform changes), the next available departure time (Digital Tourism Think Tank, 2014).

- Target Group: Domestic and foreign tourists in Switzerland.

- Augmented Reality Type: Location-Based, Image-Based

- Benefit for Tourist: Transportation, which is the biggest fear of tourists visiting the region, becomes easy, safe and fun with this application. To be able to access the hours and locations of all vehicles with the application without fear of being lost will eliminate tourists' concern and make their travel more efficient.

- Benefit for Operating: With this application, thanks to the comfort and confidence experienced by tourists coming to the region, the recommendation rate of the region to the people around them will increase and they will want to come to the region again.

- Benefit to Tourism Marketing: Transportation, which is one of the most sensitive points in tourism, can sometimes be the reason why tourists give up a destination. Therefore, with this application, the region will provide a great competitive advantage by determining its marketing strategies. 


\section{Transportation Kuoni}

As a leading travel brand, Kuoni is known as a brand that cares about innovation. Kuoni is one of the first UK tour operators which use AR where consumers will be asked to view extra content and videos on their smartphones and iPads using Aurasma's image recognition technology.Martina King, Managing Director of Aurasma said: "Kuoniare natural partners for Aurasma because, like us, their business is all about creating memorable experiences for people. This campaign is visually stunning and includes the first ever integration of a "click to call" feature in the app. This makes it engaging and fast tracks the consumer journey from print brochure to booking line." Naomi Wilkinson, Kuoni's Head of Marketing added: "With a significant proportion of our online traffic coming from smartphones and tablets, augmented reality felt like the next logical step in creating a seamless multi-channel experience for the Kuoni customer".This new innovative approach by Kuoni aims to provide the consumer with a truly multi-channel experience and reinforces his innovative belief (Kuoni, 2012).

- Target Group: Domestic and foreign tourists in the UK.

- Augmented Realty Type: Image-Based

- Benefit for Tourist: Tourists gain a lot of information flow by using this application before travelling or while travelling. Considering that satisfaction is a complete and satisfactory informationfor the tourists, it can be said that the application plays a major role in a good holiday plan or process.

- Benefit for Operating: The business that uses the application acquires a competitive advantage. It will take advantage of being the first which comes to mind with the perception it creates for tourists as well as getting help from the application providing an experience to tourists from different angles and creating a target audience.

- Benefit to Tourism Marketing: Supporting tourism with technology in the region and the opportunities offered to tourists before and after travel will bring the region to the forefront when it is evaluated from the point of the tourists. As a result of the positive perception of the tourist, the region will be more effective in terms of marketing and transportation.

\section{Transportation TravelPlot Porto}

TravelPlot Porto application which is a great way to explore the city's history is a tour guide that makes it easy to experience events, tourist destinations, wines and gastronomic areas. With 42 locations selected from 9 story sections within the application, visitors will be able to make tours according to their interests. The places in the story can be visited in chronological order. In order to determine whether the searched treasure is in the selected location, users should find it by looking at the drawings of the particular location. The application then verifies whether the treasure is within the frequency or not. Tourists visiting the city of Porto complete this tour fast and by feeling safe and entertaining at the highest levels. The application took place between June the $7^{\text {th }}$ and September the $9^{\text {th }}$ 2012; therefore some platforms/events are no longer available. Tourist can access hidden places by examining them on Facebook and twitter account (Ferreira et al., 2014).

- Target Group: Tourists in Porto.

- Augmented Realty Type: Location-Based, Image-Based

- Benefit for Tourist: Tourists who are curious about the city of Porto and wish to experience the cityby visiting can easily navigate the city of Roma with AR application interacting with social media accounts. The application offers tourists a fun experience with games by eliminating the boredom throughout their trips.

- Benefit for Operating: The application provides convenience and entertainment to the tourists being curious about the historical places of the city. It also creates satisfaction with the changes it contains. By this means, the app is expected to be the purpose for the tourists to visit the city again.

- Benefit to Tourism Marketing: Considering its potential to turn the satisfaction and being a tool into the role of being a target, it can be said that it plays a major role in the marketing and sustainability of destinations. 
Table 1: AR Usage in Tourism Industry from Businesses

\begin{tabular}{|c|c|c|c|c|c|c|c|c|c|c|c|c|c|}
\hline & $\begin{array}{c}\text { Name of } \\
\text { Business or } \\
\text { Game }\end{array}$ & 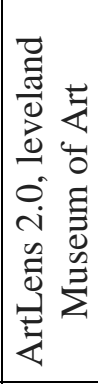 & 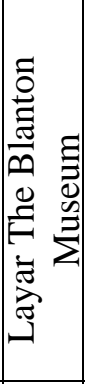 & 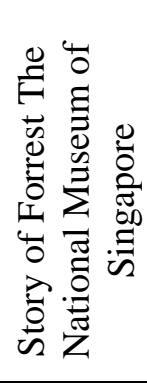 & 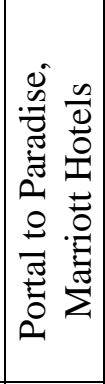 & 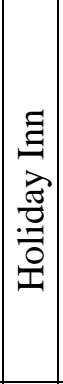 & 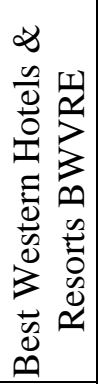 & 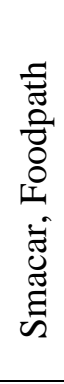 & 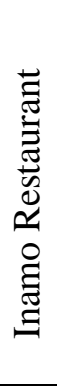 & 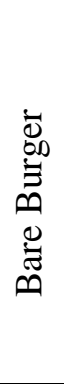 & 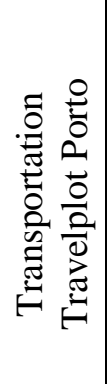 & 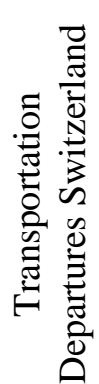 & 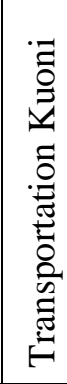 \\
\hline \multirow{5}{*}{$\begin{array}{c}\text { Type of } \\
\text { Augmented } \\
\text { Reality of } \\
\text { Application }\end{array}$} & $\begin{array}{c}\text { Location-Based } \\
\text { Augmented Reality }\end{array}$ & & & & $\mathbf{X}$ & & & & $\mathbf{X}$ & & $\mathbf{X}$ & $\mathbf{X}$ & \\
\hline & $\begin{array}{c}\text { Image-Based } \\
\text { Augmented Reality }\end{array}$ & $\mathbf{X}$ & & $\mathbf{X}$ & $\mathbf{X}$ & $\mathbf{X}$ & $\mathbf{X}$ & $\mathbf{X}$ & $\mathbf{X}$ & & $\mathbf{X}$ & $\mathbf{X}$ & $\mathbf{X}$ \\
\hline & $\begin{array}{c}\text { Projection-Based } \\
\text { Augmented Reality }\end{array}$ & $\mathbf{X}$ & & $\mathbf{X}$ & & $\mathbf{X}$ & & $\mathbf{X}$ & $\mathbf{X}$ & $\mathbf{X}$ & & & \\
\hline & $\begin{array}{l}\text { Recognition-Based } \\
\text { Augmented Reality }\end{array}$ & & $\mathbf{X}$ & $\mathbf{X}$ & & & & $\mathbf{X}$ & & & & & \\
\hline & $\begin{array}{c}\text { Outline-Based } \\
\text { Augmented Reality }\end{array}$ & & & & & & $\mathbf{X}$ & & & & & & \\
\hline \multirow{6}{*}{$\begin{array}{l}\text { The Tourism } \\
\text { Sector That } \\
\text { It Is Applied }\end{array}$} & $\begin{array}{c}\text { Business of Food- } \\
\text { Beverage }\end{array}$ & & & & & & & $\mathbf{X}$ & $\mathbf{X}$ & $\mathbf{X}$ & & & \\
\hline & $\begin{array}{c}\text { Destination / } \\
\text { Town } \\
\end{array}$ & & & & & & & & & & & & \\
\hline & $\begin{array}{c}\text { Accommodation } \\
\text { Business }\end{array}$ & & & & $\mathbf{X}$ & $\mathbf{X}$ & $\mathbf{X}$ & & & & & & \\
\hline & Travelling Agency & & & & & & & & & & $\mathbf{X}$ & & $\mathbf{X}$ \\
\hline & $\begin{array}{c}\text { Transportation } \\
\text { Business } \\
\end{array}$ & & & & & & & & & & $\mathbf{X}$ & $\mathbf{X}$ & $\mathbf{X}$ \\
\hline & Museum & $\mathbf{X}$ & $\mathbf{X}$ & $\mathbf{X}$ & & & & & & & & & \\
\hline \multirow{2}{*}{$\begin{array}{c}\text { The Features } \\
\text { of Benefit in } \\
\text { Terms of } \\
\text { Tourism } \\
\text { Marketing }\end{array}$} & $\begin{array}{c}\text { Sharing on Social } \\
\text { Media / Sharing } \\
\text { With Friends }\end{array}$ & & & & $\mathbf{X}$ & $\mathbf{X}$ & & $\mathbf{X}$ & & & & & \\
\hline & $\begin{array}{l}\text { The Opportunity } \\
\text { of Purchasing a } \\
\text { Product In } \\
\text { Application }\end{array}$ & & & & & & & & & & & & \\
\hline
\end{tabular}




\begin{tabular}{|c|c|c|c|c|c|c|c|c|c|c|c|c|c|}
\hline \multirow{5}{*}{$\begin{array}{c}\text { The Features } \\
\text { of Benefit in } \\
\text { Terms of } \\
\text { Tourism } \\
\text { Marketing }\end{array}$} & $\begin{array}{l}\text { Introduction of } \\
\text { Town/Country }\end{array}$ & $\mathbf{X}$ & $\mathbf{X}$ & $\mathbf{X}$ & $\mathbf{X}$ & $\mathbf{X}$ & $\mathbf{X}$ & & & & $\mathbf{X}$ & $\mathbf{X}$ & $\mathbf{X}$ \\
\hline & $\begin{array}{l}\text { Giving Discount/ } \\
\text { Promotion }\end{array}$ & & & & & & & & & & & & \\
\hline & $\begin{array}{c}\text { Giving } \\
\text { Information } \\
\text { About The } \\
\text { Business }\end{array}$ & $\mathbf{X}$ & & $\mathbf{X}$ & $\mathbf{X}$ & $\mathbf{X}$ & $\mathbf{X}$ & $\mathbf{X}$ & $\mathbf{X}$ & $\mathbf{X}$ & $\mathbf{X}$ & $\mathbf{X}$ & $\mathbf{X}$ \\
\hline & $\begin{array}{c}\text { Giving } \\
\text { Information } \\
\text { About The } \\
\text { Product } \\
\end{array}$ & $\mathbf{X}$ & $\mathbf{X}$ & $\mathbf{X}$ & $\mathbf{X}$ & $\mathbf{X}$ & $\mathbf{X}$ & $\mathbf{X}$ & $\mathbf{X}$ & $\mathbf{X}$ & $\mathbf{X}$ & $\mathbf{X}$ & $\mathbf{X}$ \\
\hline & $\begin{array}{c}\text { The Interactive } \\
\text { Communication } \\
\text { Between } \\
\text { Business and } \\
\text { Consumer }\end{array}$ & $\mathbf{X}$ & $\mathbf{X}$ & $\mathbf{X}$ & $\mathbf{X}$ & $\mathbf{X}$ & $\mathbf{X}$ & $\mathbf{X}$ & $\mathbf{X}$ & $\mathbf{X}$ & $\mathbf{X}$ & $\mathbf{X}$ & $\mathbf{X}$ \\
\hline
\end{tabular}

Source: Created by Authors

In Table 1. It is shown that all types of augmented reality applications are used according to the purpose of the enterprises in the field of tourism. In addition, augmented reality, which is used extensively in accommodation, transportation, food and beverage and destination marketing, is used as a great marketing tool especially in the promotion of the city, interaction with guests, promoting products, operating and promoting destinations.

\section{DISCUSSION AND RECOMMENDATIONS}

Augmented reality applications have developed continuously by developing itself since the mid19th century. Augmented reality technology is used in many fields and sectors as it is used in the tourism industry. Although the usage of the application has increased in recent years and provides advantages for enterprises, it is necessary to mention some disadvantages and difficulties as well. The complex structure and the high cost of the application cause the enterprises to abstain even if they want to use it. However, augmented reality applications, which were experienced through wearable clothing in the past, have managed to take place into mobile devices and tablets. In addition, presenting the application as a game or an activity on virtual platforms within technological devices in order to reach the consumers faster will make the augmented reality applications out of the marginal mass axis and make an application that much larger audiences desire to experience. With the increase in the use of the masses, application cost is expected to decrease. The usage of augmented reality applications in the field of tourism by many destinations and businesses will increase the competitive environment and make researches for improvements in order to provide better services to tourists. This will enable tourists to gain new and exciting experiences with different services. Considering tourism activities as an experience and need will ensure the continuity of travel of tourists.

\section{CONCLUSION}

On the basis of augmented reality, many applications have been developed and are still being developed. Today, many pilot applications and research projects are being developed. Some of the developed applications and researches are used in the tourism industry. This study aims to examine the usage of augmented reality applications in the tourism industry, the benefits and losses that may arise at present and in the future in terms of business, destination and consumer.

In this study, an in-depth literature review has been conducted and analyzed with case studies on twelve enterprises in the fields of museum, restaurant, accommodation and transportation travel businesses. As a result of the analysis, it has been observed that the use of the application in the museums provides benefits such as easy transfer of works, attracting attention and excitement, for 
tourists, it gives the opportunity to have fun while learning during their activities, spend the full time and experience the museum in different ways. It has made it possible for tourists coming to restaurants to see the food before eating and to make decisions. In addition, during the preparation of the meal by making presentations, it ensures that the customer spends time fully. It minimizes the problem of trust and prejudice, which is one of the biggest problems experienced before the holiday preference by providing the opportunity for tourists to make decisions by examining the business in the finest detail before the selection. It offers new experiences and adventures for the tourists with different applications created in the rooms and in the base area of the enterprise. This increases the sustainability and marketing power of businesses and destinations while providing consumer with an enjoyable experience. The biggest challenges for tourists in the area of transportation and travel are not to get lost while traveling to a destination or to reach the destination from the easiest way. Thanks to the augmented reality, the transportation of tourists has become easier, safer and more enjoyable. Although the application is currently being used by a limited number of businesses or destinations in the field of tourism, it is thought that this number will rapidly increase in the future.

Today, augmented reality applications, which offer enterprises a great competitive advantage in the tourism industry, are predicted to be used by many enterprises in the future. As a result, enterprises that want to gain a competitive advantage will try to make a difference with the dimensions developed within the application. It is thought that the use of augmented reality application at high levels will create great benefits for businesses in many aspects and create disadvantages in terms of employment.

This study is based on the case study on the question of "What is the place and importance of augmented reality applications in the tourism industry?" As a result of the case studies, although augmented reality applications make a great difference for the enterprises in the field of tourism, it is concluded that the usage rate is low. The application, which has not been fully understood yet by the sector managers, should be supported by studies in this field within the following years and with different perspectives on current cases. In addition, the stakeholders in the sector should be informed about the application in a detailed and instructive manner. In this sense, it is recommended that the academic circle and the sector should implement augmented reality applications in the field of tourism through common projects. If the use of application in the sector increases within a frame of purpose, it is anticipated that the problem studied in this research will be solved with easierand more reliable results in the following years.

\section{REFERENCES}

Alkhamisi, A. O. \& Monowar, M. M. (2013). Rise of Augmented Reality: Current and Future Application Areas, International Journal of Internet and Distributed Systems. 1(4), 25-34.

Arth, C. Grasset, R. Gruber, L. Langlotz, T. Alessandro Mulloni, A. \& Wagner, D. (2015). The History of Mobile Augmented Reality. Inst. For Computer Graphics and Vision Graz University of Technology, Austria.

Azuma, R. (1997). A Survey of Augmented Reality. Presence: Hughes Research Laboratories, 6(4), 355-85.

BestWestern Hotels \& Resorts (2018). Retrieved from: www.bestwestern.com/en_US/about/pressmedia/2018-press-release/bw-named-one-of-top-

10-most-innovative-companies.html

Carmigniani, J., Furht, B., Anisetti, M., Ceravolo, P., Damiani, E., \& Ivkovic, M. (2011). Augmented Reality Technologies, Systems and Applications. Multimedia Tools and Applications, 51(1), 341477.

Coates, C. (2019). How Museums are using Augmented Reality. MuseumNext, Retrieved from: www.museumnext.com/2019/02/how-museumsare-using-augmented-reality/

Cranmer, E. E. (2017). Developing an Augmented Reality Business Model for Cultural Heritage Tourism: The Case of Geevor Museum, (Dissertation), (Published Doctoral Thesis), Department of Operations, Technology, Events and Hospitality Management, Manchester Metropolitan University, Manchester.

Dieck, T. M.C. \& Jung, T. (2015). A Theoretical Model of Mobile Augmented Reality Acceptance in Urban Heritage Tourism, Current Issues in Tourism, (21)2, 1-21. 
Digital Tourism Think Tank (2014). Augmented Reality for Travel Planning, Retrieved from: www.thinkdigital.travel/opinion/augmentedreality-for-travel-planning/

Ding, M. (2017). Augmented Reality in Museums. Arts Managament \& Technology Laboratory, 3-8, Carnegie Mellon Universty, Pennsylvania.

Edwards-Stewart, A. \& Hoyt, T. \& Reger, G. (2016). Classifying Different Types of Augmented Reality Technology. Annual Review of Cyber Therapy and Telemedicine, 14, 199-202.

Ferreira, S. Alves, A. P. Quico, C. (2014) Location Based Transmedia Storytelling in Social Media Peters' TravelPlot Porto Case Study, E Review of Tourism Research (eRTR) ENTER Conference on Information and Communication Technologies in Tourism.

Han, D. I., Jung, T., \& Gibson, A. (2013). Dublin AR: Implementing Augmented Reality (AR) in Tourism, In Z. Xiang, \& I. Tussyadiah (Eds), Information and Communication Technologies in Tourism (511-523). Springer Computer Science: New York.

Jacob, J., Da Silva, H., Coelho, A. \& Rodrigues, R. (2012). Towards Locationbased Augmented Reality Games, Procedia Computer Science 15, 318-319.

Jung, T. \& Han, D. I. (2014). Augmented Reality (AR) in Urban Heritage Tourism, e-Review of Tourism Research (5), 1-5.

Kavanaugh, M. (2018). The Future of Restaurant Menus? Augmented Reality. Retrieved from: upserve.com/restaurant-insider/the-future-ofrestaurant-menus-augmented-reality/

Kounavis, C., Kasimati, A. \& Zamani, E. (2012). Enhancing The Tourism Experience Through Mobile Augmented Reality: Challenges and prospects. International Journal of Engineering Business Management, 4, 1-6.

Kuoni, (2012). Kuoni Utilise Innovative Technologies in New 2012 Brand Campaign. Retrieved from: www.prnewswire.com/newsreleases/kuoni-utilise-innovative-technologies-innew-2012-brand-campaign-137406658.html

Martins, L. M. (2017). Augmented Reality in Hotels Use Case - Holiday Inn, the first ever. Retrieved from: www.linkedin.com /pulse/augmented reality-hotels-use-case-holidayinn-first-lu\%C3\%ADs
Mekni, M. \& Lemieux, A. (2014). Augmented Reality: Applications, Challenges and Future Trends, In Applied Computational Science Proceedings of the 13th International Conference on Applied Computer and Applied Computational Science 23- 25 Kuala Lumpur, Malaysia

Pagani, A., Henriques, J. \& Stricker, D. (2016). Sensors for Location-Based Augmented Reality the Example of GALILEO and EGNOS. The International Archives of the Photogrammetry, Remote Sensing and Spatial Information Sciences, XLI-B1, 1173-1177.

Ramos, F., Trilles, S., Torres-Sospedra, J. \& Perales, F. J. (2018), New Trends in Using Augmented Reality Apps for Smart City Contexts, International Journal of Geo-Information, 7(12), $1-23$.

Reitmayr, G. \& Schmalstieg, D. (2003) Location Based Applications for Mobile Augmented Reality. Proc. 4th Australasian User Interface Conference, Adelaide, Australia,

Shabani, N., Munir, A. \& Hassan, A. (2018). EMarketing via Augmented Reality: A Case Study in the Tourism and Hospitality Industry. IEEE Potentials 38(1), 43-47

Siltanen, S. (2012). Theory and Applications of Marker-Based Augmented Reality. Sclence Technology Research Highlights Visions. VTT Technical Research Centre, Finland.

Silva, R. Giraldi, G. \& Jauvane, C. O. (2003). Introduction to Augmented Reality. Technical Report: 25/2003, National Laboratory for Scientific Computer.

Sırakaya, M., \& Seferoğlu, S. S. (2016). Öğrenme Ortamlarinda Yeni Bir Araç: Bir Eğitlence Uygulamasi Olarak Artirilmiş Gerçeklik. In A. İşman, F. Odabaşı, \& B. Akkoyunlu (Eds.), Eğitim Teknolojileri Okumaları (417-438). Adapazarı: TOJET ve Sakarya Üniversitesi.

Smacar - Foodpath. (2018). Retrieved from: smacar.com/augmented-reality-case-study restaurants-case-study-restaurants/

Taylor, M. (2018). Marriott Launches Augmented Reality App. Retrieved from: www.travelpulse.com/news/hotels-and resorts/ marriott-launches-augmented-reality-app.html

Travelplot-Porto. (2006). Retrieved from itunes.apple.com/us/app/travelplot-porto/ id530161189? $1=$ pt\&ls $=1 \& \mathrm{mt}=8$ 
Tülü, M. \& Y1lmaz, M. (2013). Iphone ile Artırılmış Gerçeklik Uygulamalarının Eğitim Alanında Kullanılması. Akademik Bilişim Kongresi, Akdeniz Üniversitesi, 23-25, Antalya.

Van Krevelen, D. W. F. \& Poelman, R. (2010). A Survey of Augmented Reality Technologies,
Applications and Limitations. The International Journal of Virtual Reality, 9(2), 1-20.

Van Krevelen, D.W.F. (2007). Augmented Reality: Technologies, Applications, and Limitations. Department of Computer Science. Vrije University, Amsterdam. 